\title{
Um Foucault desconhecido? Viagem ao Norte-Nordeste brasileiro em tempos (ainda) sombrios*
}

\author{
Heliana de Barros Conde Rodrigues**
}

Michel Foucault esteve por cinco vezes no Brasil, sempre durante os anos da ditadura militar: 1965, 1973, 1974, 1975 e 1976. Essas viagens, que constituem o tema da investigação "Michel Foucault no Brasil: presença, efeitos e ressonâncias", ${ }^{1}$ são razoavelmente conhecidas através da publicação de conferências e de notícias divulgadas na grande imprensa.

A última estada em nosso país, contudo, prossegue praticamente ignorada: em 1976, Foucault contorna os ditos "grandes centros" e visita apenas cidades do Nordeste e Norte brasileiros. Recorrendo a entrevistas sob o paradigma da história oral com aqueles que com ele conviveram à época, associadas ao divulgado na imprensa alternativa - esta o acompanhou de perto, ao contrário da grande imprensa -, o presente artigo procura reconstituir o percurso desse "Foucault desconhecido".

Em acréscimo a esse objetivo geral, o texto busca, através de seu próprio andamento, ${ }^{2}$ evidenciar o modo pelo qual as narrativas orais são incorporadas à nossa investigação: além de contribuírem para uma "história da memória"

* Versão ampliada da comunicação apresentada no XI Encontro Nacional de História Oral - Memória, Democracia e Justiça, realizado em julho de 2012.

** Professora do Departamento de Psicologia Social e Institucional/Instituto de Psicologia da Universidade do Estado do Rio de Janeiro (Uerj).

1 Financiamento: Faperj e CNPq.

2 Aliando-nos a Alessandro Portelli (2001), avaliamos que existe uma desejável indissociabilidade entre perspectiva epistemológico-metodológica e gênero narrativo em história oral. 
da presença de Foucault no Brasil, tais narrativas são vistas, na medida em que não as subordinemos a esquemas analíticos preconcebidos, como igualmente capazes de abrir caminhos de pesquisa a princípio não previstos (Portelli, 2001). Melhor dizendo, de trazer à cena memórias-resistência, memórias minoritárias, aptas a dar acesso a novas séries documentais e a conexões anteriormente insuspeitadas (Thomson, 1997).

\section{Suspeitas de Foucault, indícios de suspeição}

Nossa narrativa tem como ponto de partida o inicialmente obtido mediante pesquisa bibliográfica, de caráter biográfico ou memorialístico, à qual logo se somou alguma documentação oriunda da imprensa. Em outubro de 1975, Foucault retorna à Universidade de São Paulo (USP), onde já estivera dez anos antes (Eribon, 1990; Rodrigues, 2010). O projeto de trabalho prevê conferências sobre psiquiatrização e antipsiquiatria, e assim transmite ele, em carta a Daniel Defert (2002, p. 48), suas primeiras impressões: "Freud e Marx ao infinito. O trabalho político vem de antigos quadros sindicais ou intelectuais."

Uma série de acontecimentos logo desmentirá essa impressão de continuidade. $\mathrm{O}$ avanço da linha (mais) dura do regime sobre pessoas suspeitas de ligações com o Partido Comunista conduz Foucault, em 23/10/1975, à assembleia estudantil da USP. No dia seguinte, a Folh a de S. Paulo noticia:

Realizou-se ontem, ao meio-dia, assembléia dos alunos da USP, nas dependências da Faculdade de Arquitetura e Urbanismo, em sinal de protesto contra a prisão, ocorrida nas últimas semanas, de estudantes, professores e jornalistas. [...] O professor Michel Foucault, psicólogo 3 francês que está em São Paulo, convidado pela USP, para ministrar um curso na FFLCH, compareceu à assembléia dos alunos, ontem de manhã, e fez um pronunciamento de solidariedade aos estudantes. Disse, ainda, que pretendia suspender as aulas que está dando. (Eleições no CA..., 1975).

3 Talvez em função do prestígio adquirido por História da loucura, Foucault foi muitas vezes identificado como psicólogo pela grande imprensa brasileira. 
No mesmo dia 24/10, agentes da repressão política vão à TV Cultura para prender o jornalista Vladimir Herzog. Este consegue autorização para apresentar-se no dia seguinte à tristemente famosa Rua Tutóia ${ }^{4}$ e efetivamente o faz, na manhã de 25/10. No meio da tarde, de tão torturado, está morto. Segundo a Agência Oficial de Informações, "suicidara-se" (Gaspari, 2004, p. 174).

Se Foucault já pensava em suspender seu curso, não lhe restaram quaisquer dúvidas: em 27/10, irrompe uma greve na USP e ele lê um texto sobre o assassinato do jornalista, transformado em panfleto pelos estudantes. Em $31 / 10$, estará presente às exéquias de Herzog, que reuniram cerca de 8 mil pessoas na Praça da Sé, apesar da operação "dissuasiva” montada pela polícia na tentativa (frustrada) de impedir o acesso ao local.

Foucault permaneceu no Brasil até 11 de novembro de 1975. Ao longo dessa temporada, destacam-se contatos com a imprensa alternativa ${ }^{5}$ - uma longa entrevista ao primeiro número do periódico Versus -, bem como atividades não oficiais em âmbito universitário: uma ida à Universidade Estadual de Campinas (Unicamp), a convite do centro acadêmico; outra à Universidade do Estado da Guanabara (atual Universidade do Estado do Rio de Janeiro Uerj), onde, segundo seu biógrafo David Macey (1993, p. 350), teria pronunciando conferências sobre criminalidade, urbanização e saúde pública.

Ao deixar o Brasil, Foucault segue para Nova York. Ali, participando de uma mesa sobre "Medicina, violência e psiquiatria", juntamente com Ronald Laing, Howie Harp e Judy Clark, declara:

Perdoem-me por esta digressão que não parece falar senão incidentalmente dos asilos e não da medicina quando, de fato, nessa nova técnica de tortura foi introduzido um personagem, hoje constantemente presente no ritual de tortura: esse personagem é o médico. Praticamente em todas as torturas importantes, hoje, está presente um médico que tem por função, em primeiro lugar, dizer quais são as torturas mais eficazes; em segundo lugar, ele faz exames médicos para saber se o doente corre o risco de morrer - Herzog, morto na prisão há 10 dias, não foi suficientemente examinado - e, em terceiro lugar, o médico dá injeções de diferentes tipos para

4 Local onde estavam situadas as dependências do Departamento de Ordem Política e Social (DOI-Codi).

5 Ao que saibamos, a grande imprensa não se aproximou de Foucault no período, talvez temerosa de referências a Vladimir Herzog. 
reanimar o paciente de modo que este possa suportar fisiologicamente e psicologicamente as torturas. (Defert, 2002, p. 48). ${ }^{6}$

Tantas manifestações, no Brasil e no exterior, não terão passado despercebidas a censores de variados matizes - dos serviços de informação à imprensa guardiã da ordem ditatorial. Após o assassinato de Herzog, Foucault passou a sentir-se vigiado e temia que o regresso a nosso país lhe fosse interditado. Porém, segundo relata Eribon (1990, p. 288), estava sob a proteção do Serviço Diplomático francês e não foi incomodado. Retornará ao Brasil ainda uma vez, em 1976. Por provocação ou por prudência, a viagem prevê conferências, conforme já assinalamos, unicamente fora dos ditos "grandes centros", limitando-se ao eixo Norte-Nordeste: Salvador, Recife e Belém.

Apoiado em entrevista com Roberto Machado, escreve a respeito o jornalista Rafael Carriello (2011, p. 6):

[...] o objetivo das declarações [de repúdio à ditadura brasileira] era provocar os militares, tentar ser expulso do país e assim chamar atenção da opinião pública internacional para o que se passava no Brasil. Como não conseguiu, [Foucault] acreditou que poderia ser barrado ao tentar entrar novamente em território brasileiro, no ano seguinte, mas sua visita, organizada pela Aliança Francesa, foi autorizada.

Além do até aqui apresentado, ao iniciar a pesquisa sobre esta última visita somente dispúnhamos de memórias publicadas da professora Ieda Tucherman (2007, p. 117), que assim se referem à breve passagem do filósofo pelo Rio de Janeiro, quando recém-chegado:

Foucault $[\ldots]$ acabou por participar também de uma conversa menos formal na Aliança Francesa de Botafogo; nas casualidades da vida, eu trabalhava então na Delegação Geral das Alianças Francesas no Brasil, [...] e não apenas participei como ajudei a organizar esta conversa e ainda cuidei do transporte do conferencista, que então confessou que havia temido não obter a permissão do governo brasileiro para esta viagem.

6 Nos Cabiers de l'Herne dedicados a Michel Foucault, há um extrato dessa mesa-redonda (Foucault, 2011a), no qual não aparece o nome de Herzog. São abundantes, contudo, as menções às torturas praticadas na América Latina e no Brasil. 
Muito se tem dito serem infundados os temores do filósofo, visto que nenhum problema teria enfrentado para regressar a nosso país, mesmo depois de se recusar a ensinar "sob o tacão das botas"? "No entanto, o modo como nossa investigação se desenvolveu talvez lance novas luzes sobre essa problemática.

Praticamente sem informações sobre a visita de 1976, através de buscas na internet nos deparamos com o blog do jornalista Antonio Magalhães (2008), que, sob o título "A minha NÃO entrevista com Michel Foucault", registra:

De passagem pelo Recife, [...] Foucault foi convidado pela professora Silke Weber, da UFPE, para falar aos intelectuais do Estado. [...] Fui encarregado por Ricardo Noblat, meu chefe na sucursal da Revista Manchete, de uma conversa com o filósofo visando uma matéria que mostrasse Foucault no Recife, bem no estilo da revista, mas que dava chance ao entrevistado de expor algumas de suas idéias, bem subversivas para os militares. A princípio Silke Weber intermediou o encontro.[...] Com um gravador e roupa de trabalho fui à procura do filósofo no Hotel do Sol, em Boa Viagem. [...] $\mathrm{Na}$ recepção me informaram que ele estava na praia, defronte do hotel. Fui à praia e avistei, longe, um homem de camiseta de manga comprida preta, calção preto, óculos de aros finos e uma careca lustrosa no sol das 11 horas. Me aproximei, me identifiquei num francês capenga e disse que deveríamos procurar Silke Weber para a entrevista. [...] Voltamos ao hotel, ele foi trocar de roupa, enquanto eu aguardava Weber na recepção. A professora chegou mais séria do que nunca. Quando o filósofo desceu [...], preparei o gravador e tirei do bolso o roteiro da entrevista. Nesse momento, Weber me surpreendeu: disse que Foucault não daria a entrevista a Manchete por ser ela uma publicação reacionária [...]. Fiquei irado, tentei argumentar com Weber o valor do espaço jornalístico da Manchete, a revista mais lida pela classe média na época. "Não, não, o monsieur Foucault não vai falar para esta revista reacionária”, asseverou. E se mandou de carro com Foucault para um destino ignorado.

Ainda a respeito do ocorrido, acrescenta o jornalista, em conclusóes algo precipitadas:

A ditadura militar mexeu com o corpo e a alma dos brasileiros. Até os supostamente libertários [...] assumiram o autoritarismo latente, o stalinismo

7 Expressão de Foucault que muitos entrevistados de nossa pesquisa recordam. 
militante, que não permitem espaço para discussão de idéias. [...] Caso a Manchete fosse uma publicação mais aberta, a NÃO ENTREVISTA valeria uma matéria. Fiquei sem a entrevista e tive que topar com a cara desconfiada de Noblat. (Magalhães, 2008).

Além de facultar o acesso ao nome de uma futura entrevistada, o relato de Antonio Magalhães tornou-se "porta de entrada" para uma espécie de genealogia da suspeição associada a esse "Foucault desconhecido" que nos frequenta em tempos ainda sombrios. Passemos, pois, a algumas de suas peripécias - termo que, embora pouco acadêmico, talvez seja o que melhor retrate o que se pôde ler e, principalmente, ouvir contar...

\section{Quem é ele? Os perigos de Foucault}

Foucault já deixara Salvador, a primeira cidade visitada em 1976, quando a Folha de S. Paulo noticiou:

Envolto num proposital anonimato, o "maitre à faire" Michel Foucault desembarcou dias atrás em Salvador [...]. E por lá continua, despreocupado, sem explicar os motivos reais (se é que existem) desta sua nova incursão ao Brasil. [...] As mais recentes escavações do "arqueólogo do saber" estão agora voltadas para outra de suas curiosas teorias, a da diferenciação entre a arte erótica (tipicamente oriental) e a prática erótica (tipicamente ocidental). [...] Iconoclasta nato, o francês Foucault não está deixando por menos em seu périplo baiano: a única companhia por ele julgada conveniente em seus momentos de relax tem sido um guapo rapaz, culto e belo, conhecido naquelas plagas como Paulete. Elementar, diria, para quem costuma afirmar ter um prazer quase erótico em sua "artesania”. (Moraes, R., 1976).

Na capital baiana, são discretíssimos, na Faculdade de Filosofia e Ciências Humanas da Universidade Federal da Bahia (FCH-UFBA), campus de São Lázaro, os cartazes que divulgam a primeira apresentação do filósofo, datada de 25/10:8 "Hoje, conferência do Professor Foucault", e nada mais.

8 Apesar disso, o Livro de Presenças apresenta 105 assinaturas, encimadas pela do professor Ubirajara Rebouças, que atuou como tradutor (Pereira, 2010). 
A grande imprensa não anunciou sequer sua chegada à cidade, não obstante a Tribuna da Babia (26/10), A Tarde (27/10) e o Jornal da Babia (28/10) tenham publicado matérias a posteriori. Como será invariável no decorrer da temporada soteropolitana, a cobertura estará principalmente a cargo da imprensa alternativa: Opinião, que em 1973 focalizara minuciosamente as apresentações de Foucault na Pontifícia Universidade Católica do Rio de Janeiro (PUC-RJ), volta a fazê-lo em 1976. O exemplar inclui, além da reportagem "Interlocutores ou inimigos?" (Amaral, 1976) - na qual a polêmica com o marxismo é ativada, ${ }^{9}$ somada a desencontros com o lacanismo -, um artigo sobre o vindouro História da sexualidade 1 - a vontade de saber (Katz, 1976) e a tradução de um texto foucaultiano recente (Foucault, 1976).

Outras edições em alternativos baianos emergirão mais tardiamente: primeiro, três páginas em Invasão (Foucault, 1977), compostas de uma longa entrevista, trechos das conferências na UFBA e um cartoon de Laerte, em que Foucault aparece de rabo de cavalo. A primeira pergunta do grupo de entrevistadores é previsível: "Em que consiste seu pensamento, em linhas gerais?" Não tanto a resposta: "Eu não tenho absolutamente um pensamento, eu não funciono como um pensamento filosófico clássico [...]. Eu não tenho pensamento, tenho obsessões. Me coloco questões. Há algumas coisas que me perturbam, que me atormentam, me inquietam...." (Foucault, 1977, p. 25). Pouco adiante, indagado sobre o materialismo histórico, a nitidez da réplica leva a supor que Foucault apenas repita o muitas vezes dito, mas talvez impossível de ser ouvido no Brasil contestador da década de 1970:

Podemos fazer dois usos diferentes do materialismo dialético ou histórico, ou, se quiserem, dois usos do marxismo - um que consiste precisamente em recodificar toda a história para reproduzir uma representação filosófica dela, e uma utilização metodológica, quase técnica, de um certo número de conceitos [...]. No primeiro caso, você tem o marxismo tal como é praticado nas universidades [...], e no segundo caso, você faz um uso tático e estratégico do marxismo, de um certo número de conceitos fundamentais do marxismo que permite decifrar uma situação, analisar um tempo histórico etc. (Foucault, 1977, p. 25).

9 É esta a polêmica privilegiada, tanto que a matéria assim termina: "Entre as sombras ficou a dúvida: quem são os 'marxistas academicistas' a quem [Foucault] critica tão intensamente? Interlocutores ou inimigos?” (Amaral, 1976, p. 18). 
Menos obcecado com o contraponto Foucault versus Marx, será um nanico anarquista aquele que irá garantir preciosos registros ${ }^{10} \mathrm{da}$ passagem de Foucault pela capital baiana. Dividida em duas edições, a conferência intitulada As malhas do poder será futuramente publicada em Barbárie (Foucault, 1981, 1982). Segundo Pereira (2010), à época o texto circulou de modo restrito, em função da pequena tiragem do periódico. ${ }^{11}$ No entanto, "seguiu sendo reproduzido através de processo xerográfico, tornando-se para alguns estudantes da FFCH uma espécie de texto cult, que vez por outra encantava quem o descobria [...]; ele continua sendo redescoberto por jovens, hoje mais que outrora" (Pereira, 2010, p. 8).

Esse Foucault simultaneamente famoso e ignorado, reverenciado e desconhecido, reaparece a cada desdobramento de nossa investigação. Conta-nos uma vez mais Pereira (2010) que o filósofo se divertia com essa circunstância: em certa ocasião, na Estrada de São Lázaro, a caminho da faculdade, "foi perseguido por alguns garotos de rua que o chamavam de Kojak, identificando-o como Telly Savalas, protagonista de um seriado que naquele momento passava na televisão. Foucault comentou alegre que eles não o conheciam, mas pelo menos conheciam o Kojak!" (Pereira, 2010, p. 11).

Em 1976, contudo, ignorar a existência de Foucault não era privilégio da meninada das ruas de Salvador. A professora Sonia Sampaio, que àquela altura recém concluíra o curso de psicologia, diz-nos que passeava pelo campus de São Lázaro quando avistou, na varanda do "Casarão", um homem careca, roupa preta, gola rolê, olhar penetrante. Surpresa, perguntou ao professor Ruy Simões: “Quem é ele?” Recebeu do velho mestre uma resposta entre espantada e entusiasta: "É Foucault!!!" Na década de 1990, durante o doutoramento em Educação na UFBA, Sonia Sampaio empolga-se com a leitura de Microfísica do poder e Vigiar e punir, já que sua pesquisa se volta para o corpo na escola. O orientador a desanima, alegando: "Mas é... um estruturalista!" Como resultado, na tese ${ }^{12}$ há apenas uma nota de rodapé, de

10 As malhas do poder é um dos textos brasileiros publicados em Dits et écrits, em (re)tradução para o francês por Plínio Wander Prado Júnior. Em português, foi estabelecido com base na tradução da conferência e dos debates por Ubirajara Rebouças.

11 A Bahia teve outras publicações anarquistas: Metanóia, que durou de 1977 a 1979, e O inimigo do rei, que se prolongou de 1977 a 1988. Neste último encontraremos o texto "As manhas do poder" (Foucault, 1979a, p. 8) - aula no Collège de France posteriormente publicada em Microfísica do poder como "Soberania e disciplina" (Foucault, 1979c).

12 Ver Sampaio (1997). 
cerca de quatro linhas, em que a autora menciona os livros acima citados, afirma que "todo mundo conhece Foucault" e o abandona, porque "fora do escopo do trabalho". Porém em 1976, ressalta Sonia Sampaio, "ele era apenas aquele cara na varanda...." ${ }^{13}$

De Salvador, Foucault segue para Recife. Está acompanhado de Roberto Machado e sua anfitriã na cidade, como sabemos, é Silke Weber - os dois o haviam encontrado previamente em Paris para combinar a programação. Antes da chegada do filósofo, muitos compromissos tinham sido agendados com profissionais e acadêmicos da cidade, interessados em contatos mais próximos do que os possíveis em conferências oficiais. Entretanto, a oficialidade irá predominar: segundo as lembranças de Silke Weber, às vésperas dos encontros informais previstos, alguém sempre telefonava para desmarcá-los, em claro indicativo do temor que as pessoas experimentavam em se verem associadas a Foucault. Este, que, ainda nas palavras da professora, ignorava o que estava acontecendo, queixou-se do exagerado tempo livre de que dispunha, acusando os organizadores de o terem colocado em uma "cage d'or" - referindo-se à hospedagem no Hotel do Sol, não tão luxuoso assim, mas situado em frente à (então) paradisíaca Praia de Boa Viagem. ${ }^{14}$

Recente matéria de Fabiana Moraes (2012), além de abordar esses "temores", traz à cena a programação oficial na Universidade Federal de Pernambuco (UFPE) e as tentativas dos organizadores de preencher o tempo esvaziado pelos sentimentos (ditatoriais) de perseguição. Quanto ao primeiro aspecto, afirma a jornalista:

Um daqueles que cutucou o filósofo com o "Barbudo" [Marx] durante o minicurso realizado no prédio do Centro de Filosofia e Ciências Humanas foi Gadiel Perrusi, ${ }^{15}$ hoje professor aposentado do Programa de Pós-Graduação em Sociologia. "Foucault disse que a trajetória cultural do mundo ocidental havia começado na Idade Média, no momento em que se instituiu a confissão católica. Eu pensei 'ai meu Deus do céu'... e perguntei, com muito cuidado, se nossa trajetória não havia começado com a acumulação primitiva do capital", conta. Foucault, que gostava de ter a última palavra,

13 Entrevista concedida por Sonia Sampaio em 13/07/2010, Salvador.

14 Entrevista concedida por Silke Weber em 28/04/2010, Recife.

15 Tive uma entrevista telefônica com Gadiel Perrusi, em Recife (30/04/2010), quando o professor fez um relato bem próximo do apresentado pela jornalista. 
foi enfático. "Eu tenho o direito de criar a minha própria periodicidade." (Moraes, F., 2012).

Já no que tange às estratégias para que Foucault não se sentisse tão “enjaulado", podemos ler na mesma matéria jornalística:

Distanciamentos intelectuais à parte, Gadiel Perrusi [...] levou o filósofo para uma série de locais, procurando entretê-lo, tarefa que compartilhou com Silke Weber e Maud Fragoso. ${ }^{16}$ [...] Foi uma espécie de Amazing Race intelectual, onde não faltou atração turística [...]: Perrusi o acompanhou a Igarassu, onde visitaram a Igreja de São Cosme e Damião, e ao Convento de Santo Antônio e ao Engenho São João, em Itamaracá. [...] Com Silke, ainda acompanhou Foucault à antiga Casa de Detenção do Recife, atual Casa da Cultura. O espaço era de especial interesse, já que [...] o projeto arquitetônico é de origem francesa, quase cópia das antigas prisões gaulesas. Mais: o projeto de Mamede Ferreira (1850) segue o modelo extensamente estudado por Foucault e seus tantos seguidores, o panóptico de Jeremy Bentham em 1785. (Moraes, F., 2012).

Ao deixar Recife, Foucault dirige-se a Belém. O encontro com pessoas interessadas no pensamento do filósofo fora minuciosamente preparado pelo professor Benedito Nunes ${ }^{17}$ e, dessa feita, como ele próprio relata, não houve "fugas":

[...] justamente para que as conferências fossem proveitosas eu peguei a turma da filosofia e fiz uma série de exposições sobre o Foucault [...]. Então, para assegurar a presença de pessoas que tinham um conhecimento de francês e que estavam manifestamente interessadas, eu fiz uma relação que contava sessenta assistentes. Aquela lista foi uma espécie de marco de fidelidade, de que as pessoas iam comparecer e etc. Foucault foi extraordinário [...]. Eu fazia a intermediação, as pessoas faziam as perguntas, eu traduzia, ele dava as respostas e eu passava para a assistência. (Nunes, 2008, p. 21-22).

16 Maria Izabel Pitanga, bolsista de Iniciação Científica, realizou longa entrevista, em Recife, com Maud Fragoso (14/11/2011). Quando da estada de Foucault, ela preparava sua dissertação de mestrado, que viria posteriormente a ser publicada em livro (Perruci, 1983).

$17 \mathrm{O}$ acesso ao nome do professor Benedito Nunes e à entrevista mencionada em sequência foi proporcionado pelo professor Ernani Chaves, a quem agradecemos. 
A fidelidade da assistência, todavia, não pôde garantir a sobrevivência desses "ditos" foucaultianos: "Tivemos um jantar de despedida em um restaurante $[\ldots]$. Ainda havia uma moça paulista que nos acompanhava sempre, e todas as fitas gravadas das palestras do Foucault foram roubadas do carro dela" (Nunes, 2008, p. 22).

Talvez certa decepção se tenha seguido a essa ocorrência. Mas houve maiores riscos, de desaparecimentos outros:

Menos de uma semana depois que Foucault foi embora, fui chamado pelo diretor, cujo nome não vou mencionar, me dizendo que o SNI estava pedindo a relação dos freqüentadores. Eu disse "eu não dou a relação". Saí de lá e fui diretamente falar com o reitor. Ele foi muito correto, e até corajoso. Ele me disse para não dar a lista. [...] Havia uma vigilância até nesse ponto. Não era uma invenção dizer que o SNI estava infiltrado. (Nunes, 2008, p. 22).

Portanto, se Foucault não teve problemas para voltar ao Brasil, aqueles que dele se aproximaram poderiam tê-los experimentado, não fosse a "coragem do silêncio" de alguns universitários de Belém.

\section{Arquivos da suspeição}

Como vimos até o momento através dos relatos de nossos entrevistados, algumas ocorrências associadas à presença de Foucault no Brasil em 1976 mais parecem confirmar os resultados de suas pesquisas sobre os modos contemporâneos de exercício do poder do que descartar, como ilusória, a vigilância dos serviços de informação sobre seus passos.

Esses indícios orais levaram-nos a solicitar, ao Arquivo Nacional, uma consulta aos dados porventura existentes sobre Michel Foucault nos acervos ligados aos organismos de segurança do regime militar. ${ }^{18}$ A resposta obtida foi surpreendente, revelando que o filósofo estava sob vigilância antes mesmo de seu envolvimento nos protestos pelo assassinato de Vladimir Herzog. Eis parte do texto de um dos documentos obtidos, provavelmente redigido por um agente infiltrado:

18 A iniciativa partiu de Maria Izabel Pitanga, bolsista de Iniciação Científica (CNPq). 
O epigrafado é considerado como um dos maiores filósofos da atualidade, conhecido internacionalmente. Pertence à corrente anti-marxista, conhecida na França como Democracia Socialista. Foi “manobrado” a tomar posição contra o governo, na assembléia do dia 23/10, na FAU pelos docentes do Departamento de Filosofia da F.F.L.C.H.-USP, Maria Sylvia de Carvalho Franco Moreira e Marilena Chauí Tosta Berlinck, conhecidas pela atuação esquerdista dentro da Faculdade. (Documento ASP/SNI nr. 5325, 31/10/1975, p. 5).

Já o pronunciamento de Foucault contra o governo, na mesma assembleia, é assim transcrito em novo documento:

Muitas dezenas de estudantes e professores da USP foram recentemente presos. Talvez sejam torturados - se é que já não o estão sendo neste momento. Suas vidas estão ameaçadas. Uma Universidade que não é plenamente livre não passa de uma empresa de servilidade. Não dá para lecionar sob o tacão das botas; não dá para falar diante dos muros das prisões; não dá para estudar quando as armas ameaçam. A liberdade de expressão e de pesquisa são sinais de garantia da liberdade dos povos. Na defesa dos direitos, na luta contra as torturas e a infâmia da polícia, as lutas dos trabalhadores intelectuais se unem à dos trabalhadores manuais. A Universidade de São Paulo saiba que sua luta de hoje relaciona-se à luta pela liberdade em todos os países do mundo. Presto minhas homenagens à sua coragem e me associo de bom grado às decisões que vocês possam tomar para conseguir que a justiça aqui não seja uma palavra ultrajada. (Informação nr. 5497, 14/11/1975, p. 1).

Cumpre ressaltar que os informes do SNI parecem estranhamente empenhados em "inocentar" Foucault de seu próprio discurso, ao mesmo tempo que multiplicam suspeições outras:

Constata-se pelo teor do comunicado do Prof. Foucault que é um documento redigido por aqueles docentes [Maria Sylvia de Carvalho Franco e Marilena Chauí], pois o nominado não escreve corretamente a língua portuguesa. Pode ser, também, uma provocação aos órgãos de segurança para que detenham o professor, e consequentemente seria criado um caso de repercussões negativas para o Brasil no exterior. $\mathrm{O}$ nominado não possui oficialmente mais nenhum vínculo com a Universidade. Constata-se 
mais uma vez, que as Universidades contratam docentes no Exterior, sem exigir sequer os dados de qualificação. (Documento ASP/SNI nr. 5325, $31 / 10 / 1975$, p. 5$) \cdot{ }^{19}$

Soa no mínimo paradoxal perceber que enquanto a intelectualidade contestadora discute se Foucault é, ou não, marxista, o SNI se considera onisciente seja quanto às posições políticas do filósofo - "Não é comunista", insiste outro informe -, seja no que tange a suas possibilidades e impossibilidades discursivas, associando-as a "manobras" e "interesses" alheios - "está sendo usado pelos alunos e professores interessados em criar um impasse internacional", reafirma o mesmo informe (Informação nr. 2044-B/75, 28/10/1975).

\section{Considerações finais}

A reconstituição empreendida no presente artigo sugeriu não ser mera fantasia a vigilância sobre Foucault desencadeada pela ditadura militar - em parte responsável, talvez, pelo fato de não mais ter ele retornado ao Brasil após 1976. ${ }^{20}$ Paralelamente, permitiu explorar contrastes entre jornais locais, grande imprensa e imprensa alternativa quanto à apreciação da presença e das ideias do filósofo em tempos (ainda) sombrios de nosso país.

No entanto, mais do que uma sempre problemática comprovação de "fatos", o estabelecimento de correlações entre fontes escritas e relatos orais nos tem propiciado algumas aventuras em termos de pesquisa histórica. Destacamos três delas: a ênfase na tensão entre as memórias cristalizadas e as memórias-resistência; o desenvolvimento de uma estratégia investigativa mais cartográfica do que estritamente metodológica; a possibilidade de levar em consideração múltiplos sentidos para o tempo.

19 A documentação do SNI relativa a Michel Foucault comporta ainda uma série de ofícios e memorandos internos à FFLCH-USP, mostrando o quanto a universidade era permeável aos controles ditatoriais.

20 Alternativamente, tem sido afirmado que Foucault deixou de vir ao Brasil em decorrência de sua paixão pelos Estados Unidos e do prestígio lá adquirido. As duas hipóteses não são, evidentemente, incompatíveis. 
Quanto ao primeiro aspecto, acompanhando Portelli (1996) e Pollak (1989), assinalamos a inadequação da expressão "memória coletiva". ${ }^{21}$ Sem descartar a relevância de Halbwachs (1956) e seus seguidores para os estudos de história da memória, cumpre frisar que o termo "coletivo" mais se preste, provavelmente, a designar "lugares da memória" (Nora, 1984-1992) do que a singularizar o caráter das narrativas orais. Em tais narrativas, se os instituídos jamais se ausentam - evoquemos as referências à vigilância sobre Foucault como fantasiosa -, tampouco deixam de emergir memórias que poderíamos denominar, na esteira do pensamento de Deleuze (1996) e do próprio Foucault (1979b), minoritárias, insurgentes ou contracondutuais - os relatos de Silke Weber e Benedito Nunes sobre as ocorrências de 1976 nos parecem bastante significativos nesse aspecto.

No que tange à cartografia - procedimento que se desenvolve acompanhando os movimentos do campo em análise, em lugar de fixar, prévia e "metodologicamente", os territórios a explorar -, importa ressaltar o valor das narrativas orais na elaboração, a cada momento, dos passos sequenciais da pesquisa. Jamais teríamos pensado, por exemplo, em consultar os arquivos do SNI, não fosse a insistência, por parte de alguns de nossos entrevistados, na existência de um permanente clima de suspeição ao longo da passagem de Foucault pelo Norte-Nordeste.

Porém, e talvez principalmente, é preciso fazer referência ao tempo: não apenas a Cronos, com suas sequências mensuráveis e espacializáveis, mas igualmente a Kairós - o tempo oportuno - e a Aión - o jorrar do tempo (Rodrigues; Penzim, 2011). Pois o quanto nos perturba, desejavelmente por sinal, perceber que a última presença de Foucault no Brasil mobiliza lembranças intempestivas, rebeldes às sequências tranquilizadoras, evocando um momento que era preciso "agarrar"; e, igualmente, verificar que essa mesma presença aponta para partições imprevistas entre passado, presente e futuro, impossíveis de pôr em correspondência biunívoca com o tempo cronológico, com o tempo tranquilizador do calendário.

Nesse sentido, uma certa conjugação do minoritário, do cartográfico e do intempestivo nos dirigiu a uma fonte a mais: os protestos, ao final de

21 Portelli (1996) rejeita igualmente a expressão "memória dividida”, pois menos se trata de antagonismos entre memórias de classes ou grupos opostos que de relações agonísticas entre memórias diversificadas. Já Pollak (1989) vê na história oral contemporânea uma denúncia do caráter uniformizador da memória coletiva, podendo-se afirmar, consequentemente, que com ela a memória entra em disputa. 
2011, dos estudantes da USP quanto à ação da polícia no campus e a análise correlata, por eles realizada, das atitudes tomadas pelos professores da universidade. Na "Carta do comando de greve dos estudantes da FAU aos membros da congregação", postada em 17/12/2011 no blog que divulgava os acontecimentos, pode-se ler:

No dia 08.11.11 vimos uma ação desproporcional da polícia militar e do governo do estado dentro da universidade de São Paulo. Vimos 400 soldados da tropa de choque, GATE, GOE, cavalaria dentro do campus para reprimir uma manifestação política [...]. No mesmo dia, uma assembleia histórica dos estudantes da USP deliberou pela greve imediata [...]. Os professores se posicionaram em manifesto contra o autoritarismo na USP e ao mesmo tempo seguiram agindo normalmente [...]. Como podem os professores da considerada melhor universidade do país manter a normalidade, continuando com suas pesquisas e aulas enquanto 73 estudantes são presos por manifestarem-se politicamente? Qual é o projeto de ensino de professores que [...] se abstêm da capacidade de pensar um projeto de universidade real que possa superar as formas retrógradas e autoritárias da nossa academia? Caros membros da congregação, requeremos um posicionamento. Assim como fez Niemeyer em 1969 que cancelou palestra a ser realizada na FAU em solidariedade a Artigas e Paulo Mendes da Rocha que acabavam de ser exilados. Assim como fez Foucault no Brasil em 1975, que interrompeu sua palestra ao saber das prisões deflagradas pelos agentes do regime militar em São Paulo, declarando "não há pensamento livre sob a bota dos militares”. (Carta do comando..., 2011).

Particularmente, vale a pena citar a frase seguinte (e última) dessa mesma carta: "Estes são nossos verdadeiros mestres."

Ressoando no presente e um pouco menos "desconhecido", agora, mediante nosso breve artigo, esse Foucault anarqueólogo - termo que ele próprio utilizou, durante um curso no Collège de France, para se autodenominar (Foucault, 2011b) - poderá, aspiramos, ajudar a multiplicar nossas lutas, inevitavelmente situadas e parciais, porém sempre intransigentes, por autogoverno e liberdades. 


\section{Referências}

AMARAL, J. J. C. Interlocutores ou inimigos? Opinião, n. 211, p. 18, 19 nov. 1976.

CARRIELLO, R. Sócrates no calçadão. As viagens de Foucault ao Brasil. Folha de S. Paulo, São Paulo, 22 maio 2011. Ilustríssima, p. 6.

CARTA DO COMANDO de greve dos estudantes da FAU aos membros da congregação. USP em Greve, 17 dez. 2011. Disponível em: <http://uspemgreve.blogspot.com. br/2011/12/carta-do-comando-de-greve-da-fau-aos.html>. Acesso em: 10 maio 2012.

DEFERT, D. Cronologia. In: FOUCAULT, M. Ditos e escritos 1: problematização do sujeito, psicologia, psiquiatria e psicanálise. Rio de Janeiro: Forense Universitária, 2002. p. 1-70.

DELEUZE, G. Lo que dicen los niños. In: DELEUZE, G. Crítica y clínica. Barcelona: Anagrama, 1996.

ELEIÇŌES NO CA Onze de Agosto. Folha de S. Paulo, São Paulo, p. 17, 24 out. 1975.

ERIBON, D. Michel Foucault: uma biografia. São Paulo: Companhia das Letras, 1990.

FOUCAULT, M. O ocidente e a verdade do sexo. Opinião, n. 211, p. 20-21, 19 nov. 1976.

FOUCAULT, M. As obsessões de Michel Foucault. Invasão, p. 25-27, mar. 1977.

FOUCAULT, M. As manhas do poder. O inimigo do Rei, ano 3, n.1, p. 8, 1979a.

FOUCAULT, M. Genealogia e poder. In: FOUCAULT, M. Microfisica do poder. Rio de Janeiro: Graal, 1979b. p. 167-177.

FOUCAULT, M. Soberania e disciplina. In: FOUCAULT, M. Microfisica do poder. Rio de Janeiro: Graal, 1979c. p. 179-191.

FOUCAULT, M. As malhas do poder. Barbárie, n. 4, p. 23-27, verão de 1981.

FOUCAULT, M. As malhas do poder. Barbárie, n. 5, p. 34-42, verão de 1982.

FOUCAULT, M. Réponse à Ronald Laig. In: ARTIÈREs, Ph. et al. (Org.). Cahier de l'Herne: Foucault. Paris: Éditions de L'Herne, 2011a. p. 103-104.

FOUCAULT, M. Do governo dos vivos: curso no Collège de France, 1979-1980 (excertos). São Paulo: Centro de Cultura Social; Rio de Janeiro: Achiamé, 2011b.

GASPARI, E. A ditadura encurralada. São Paulo: Companhia das Letras, 2004. 
HALBWACHS, M. La mémoire collective. Paris: PUF, 1956.

KATZ, C. S. Reich, sexo e poder. Opinião, n. 211, p. 18-20, 19 nov. 1976.

MACEY, D. The lives of Michel Foucault. New York: Vintage Books, 1993.

MAGAlHÃeS, A. A minha NÃO entrevista com Michel Foucault. Blog Antonio Magalhães, 1 jul. 2008. Disponível em: <http://www.antoniomagalhaes.com.br/?p=66>. Acesso em: 9 set. 2009.

MORAES, F. Na "gaiola de ouro" da nossa consciência. Pernambuco: Suplemento Cultural do Diário Oficial de Pernambuco, p. 10-13, abr. 2012.

MORAES, R. Foucault na Bahia, atrás de Eros. Folha de S. Paulo, São Paulo, p. 33, 19 nov. 1976.

NORA, P. (Dir.). Les lieux de mémoire. Paris: Gallimard, 1984-1992. 7 v.

NUNES, B. Entrevista com Benedito Nunes. Trans/Form/Ação, São Paulo, v. 31, n. 1, p. $9-23,2008$.

PEREIRA, C. L. Apontamentos sobre os devaneios soteropolitanos do arquivista feliz. In: PRIMEIRO ENCONTRO DOS PROGRAMAS DE PÓS-GRADUAÇÃO DA UFBA, Salvador, 2010. Mimeografado.

PERRUCI, M. F. de A. Mulheres encarceradas. São Paulo: Global, 1983.

POLLAK, M. Memória, esquecimento, silêncio. Estudos Históricos, v. 2, n. 3, p. 3-15, 1989.

PORTELLI, A. O massacre de Civitella Val di Chiana (Toscana, 29 de junho de 1944): mito, política, luto e senso comum. In: FERREIRA, M. M.; AMADO, J. (Org.). Usos e abusos da história oral. Rio de Janeiro: FGV, 1996. p. 103-130.

PORTELLI, A. A História Oral como gênero. Projeto História, n. 22, p. 9-36, jun. 2001.

RODRIGUES, H. de B. C. Um (bom?) departamento francês de ultramar. Michel Foucault no Brasil, 1965. Mnemosine, v. 6, n. 2, p. 183-200, 2010.

RODRIGUES, H. de B. C.; PENZIM, A. M. B. Cronos, Kairós, Aión. Temporalidades de uma visita de Michel Foucault a Belo Horizonte. Cadernos Brasileiros de Saúde Mental, v. 3, n. 6, p. 1-16, 2011.

SAMPAIO, S. M. R. O corpo no cotidiano escolar e a miséria da pedagogia. Tese (Doutorado em Educação)-Faculdade de Educação. Universidade Federal da Bahia, Salvador, 1997. 
THOMSON, A. Recompondo a memória. Questões sobre a relação entre a história oral e as memórias. Projeto História, n. 15, p. 51-71, abr. 1997.

TUCHERMAN, I. Michel Foucault, hoje ou ainda: do dispositivo de vigilância ao dispositivo de exposição da intimidade. In: QUEIROZ, A.; CRUZ, N. V. (Org.). Foucault hoje? Rio de Janeiro: 7 Letras, 2007. p. 108-118.

Resumo: Michel Foucault esteve por cinco vezes no Brasil, sempre durante os anos da ditadura militar: 1965, 1973, 1974, 1975 e 1976. Essas viagens são razoavelmente conhecidas mediante conferências publicadas e notícias divulgadas na grande imprensa. A última estada de Foucault em nosso país, no entanto, tem características singulares: após seus protestos, em 1975, quando do assassinato do jornalista Vladimir Herzog nos porões do DOI-Codi, o filósofo julgava que não obteria novo visto de entrada. Sendo assim, em 1976, ele contorna os "grandes centros" e visita apenas cidades do Nordeste e Norte brasileiros. O presente artigo procura reconstituir esse percurso menos conhecido de Foucault no Brasil, recorrendo, para tanto, a entrevistas sob o paradigma da história oral com alguns daqueles que com ele conviveram à época, associadas ao divulgado na imprensa alternativa. A reconstituição empreendida sugere não ser uma simples fantasia a vigilância sobre Foucault desencadeada pela ditadura militar, em parte responsável, talvez, pelo fato de o filósofo não mais haver retornado ao Brasil após 1976. Nesse aspecto, as narrativas orais ensejaram caminhos de pesquisa inicialmente não previstos, como a consulta aos documentos do Serviço Nacional de Informações (SNI) disponíveis no Arquivo Nacional.

Palavras-chave: Foucault, Brasil, ditadura militar, memórias.

\title{
An unknown Foucault? Journey to the North-Northeast Brazil in dark times
}

\begin{abstract}
Michel Foucault has visited Brazil five times, always during the years of military dictatorship: 1965, 1973, 1974, 1975 and 1976. These trips are well known through the published conferences and the news in the mainstream press. However, Foucault's last stay in our country has unique characteristics: after his protests in 1975, when the journalist Vladimir Herzog was murdered in the basements of DOI-Codi, the philosopher thought he wouldn't get a new visa. Thus, in 1976, he avoids the "big cities" and he only visits some North and Northeast Brazilian cities. This paper seeks to reconstitute this less known Foucault's pathway. It appeals to the interviews, under the paradigm of Oral History, with some of those who met Foucault at the time, related to what was reported in the alternative press. The reconstitution undertaken suggests that the surveillance on Foucault, triggered by Military Dictatorship, is not a simple fantasy and that it was perhaps partly responsible by the fact that the philosopher has no longer returned to Brazil after 1976. In this aspect, the oral narratives has favored research paths not initially foreseen, such as the consultation of SNI documents available in the National Archives.
\end{abstract}

Keywords: Foucault, Brazil, military dictatorship, memories. 